\title{
Priority goals for the strategic development of industrial enterprises based on sustainable marketing
}

\author{
Yulia Medvedeva ${ }^{1, *}$, Maria Kolgan ${ }^{1}$, Maksim Pasholikov ${ }^{2}$, Yuriy Shevyakov ${ }^{3}$, and Alisa \\ Sidorenko ${ }^{3}$ \\ ${ }^{1}$ Don State Technical University, 1, Gagarin Square, Rostov-on-Don, 344000, Russia \\ ${ }^{2}$ Peter the Great St. Petersburg Polytechnic University, 29, Politechnicheskaya St., Saint Petersburg, \\ 195251, Russia \\ ${ }^{3}$ Belgorod State University, 85, Pobedy St., Belgorod, 308015, Russia
}

\begin{abstract}
The article was prepared on the basis of the conceptual research method that relies on the study of academic literature to find and integrate various concepts, including aspects of sustainable development, marketing management of an industrial enterprise, organizational levels of decisionmaking, and strategic management. The proposed method to determine the goals for sustainable strategic development of industrial enterprises involves assessing the priorities of stakeholders' interests based on the Mitchell-Agle-Wood Salience Model. Identification of stakeholders, determination of the importance of each of the groups and ranking of their sustainable development goals allow industrial enterprises to justify the concentration of resources in the most important areas of sustainable development for enterprises. The algorithm makes it possible to provide a deeper insight into the stakeholders surrounding the enterprise, due to the fact that the interests of those participating in the business processes are taken into account, which subsequently will have a positive effect on meeting the strategic goal of the enterprise. This allows stakeholders and enterprises to avoid unnecessary expenses and to increase the efficiency of the developed programs. The results obtained would be useful for practitioners who determine the strategic direction of industrial enterprises and are looking for sustainable mechanisms for joint marketing management.
\end{abstract}

\section{Introduction}

Over the past decades, sustainable development has become relevant in the modern economy. In connection with the increased academic attention to aspects of sustainable development, such concepts as sustainable development and corporate social responsibility are expanded and eroded, especially at the corporate level. All of the terms seem to share a common direction: the main objective is to take into account company's environment and stakeholders, which means being accountable to them for the performance and impact, not

\footnotetext{
* Corresponding author: jjmedvet@yandex.ru
} 
just for the interests of shareholders and owners. The sustainable development of the economy is of both general economic and sectoral nature [1].

In response to the actualization of sustainable development, the concept of sustainable marketing is being formed, which includes the building and development of sustainable relations with the environment and the creation of new consumer value through the integration of environmentally friendly technologies to produce goods and services, a culture of consumption and ethically verified solutions for managing marketing interaction [2].

The relevance of this study is determined by the fact that the application of the modern concept of sustainable marketing by enterprises can ensure the implementation of the process of economic and social change, in which natural resources, the direction of investment, the orientation of scientific and technological development, personal development and institutional changes are consistent with each other and strengthen the current and future potential to meet human needs.

Typical features of the modern industrial market environment are commoditization, consolidation of consumers, bargaining power shift from sellers to buyers, and margin erosion. This creates the need to focus on customer value [3]. The growth of commoditization is driven by the increasing consumption of know-how and rapidly developing competition, when initially unique products and services have lost their distinction and value. At the same time, customers are consolidating across multiple markets. As a result, a few key customers increasingly concentrate sales and profits. This is reflected in the concentration of trade and the emergence of trade networks. A direct consequence of the trend is a general shift of bargaining power from sellers to buyers. The combined impact of commoditization on customer concentration and bargaining power shift from sellers to buyers has decreased business profitability [4].

The growing problem of margins came along with mounting pressure on management to increase the profitability and value of companies. As a consequence, short-term marketing costs and long-term investments were reduced. Such decisions made by companies cannot lead to good results in the long term. Traditional market methods offer only a few ways to deal with margin dilutions or presuppose extensive work with very limited results.

The above-mentioned changes in market conditions and the growing intensity of competition associated with the global economic crisis put pressure on companies. Most companies are faced with the challenge of how to change their market strategy and tactics in their target markets to mitigate the negative impact of the current recession. To solve the problem, we need a different attitude to the strategic management organization.

\section{Materials and methods}

The concept of sustainable marketing was proposed in 1995 by J. Sheth and A. Parvatiyar who defined it as 'a way to reconcile economic and environmental factors through innovative goods and production systems' [1]. In 1996, Y. van Dam and P. Apeldoorn described sustainable marketing as a way of organizing the market activity of an enterprise in a limited ecological space [5].

The study of modern approaches to understanding the essence of sustainable marketing shows the environmental aspect prevails in the interpretation of this concept [6]. However, there is a new approach to the organization of sustainable marketing based on building long-term mutually beneficial relationships between market participants. In 2010, R. W. Mitchell, B. Wooliscroft and J. Higham identified the need for a broader conceptualization of market orientation, and for the development of a new corporate marketing model: sustainable market orientation (SMO) [7]. The proposed concept assumes the use of three 
key goals of sustainable development in the corporate marketing strategy: economic, social and environmental sustainability.

In the modern interpretation, sustainable marketing determines the long-term orientation of relationship marketing, in contrast to the short-term transactional orientation of modern marketing $[8,9]$.

Companies need to take it into account that sustainability ceased being a variable component of competitive advantage and has become its necessary requirement. This is, in fact, a business requirement because the concept of marketing is not limited to personal and interpersonal needs, but expands towards the needs of future generations [10].

The top priority in modern sustainable marketing is to deliver sustainable value to customers. In doing so, companies must adopt an ecosystem mindset and collaborate with various stakeholders [11].

The challenge for sustainable marketing is to ensure that management is focused on the company's interactions with key stakeholders. Sustainable enterprise resource planning is a corporate system that incorporates the main elements of a corporate sustainable value chain into a centralized system [12]. It is a massive information system, and its deployment is costly and time consuming. Poor planning, limited resources, and lack of commitment can lead to a system failure. Several studies have discussed the concept of sustainable enterprise resource planning systems. However, little research has focused on the organization aspect of sustainable development priority selection that can guide practitioners in implementing sustainable enterprise marketing. To close this gap, the objective of the study is to develop a method for selecting the priority goals of an enterprise to justify the concentration of resources on the most important areas of sustainable development for enterprises.

The article was prepared on the basis of the conceptual research method that relies on the study of academic literature to search and integrate various concepts, including aspects of sustainable development, marketing management of an industrial enterprise, organizational levels of decision-making, and strategic management.

\section{Results}

Both the need to adapt the enterprise to the changing market environment and restructuring of economic and financial activities in response to market challenges make it difficult for the top management to choose strategic development alternatives and to make strategic decisions. Economists offer new concepts of enterprise development, one of which is the concept of sustainable development [13].

Sustainable industrial enterprise management has a number of benefits: identifying areas that create long-term value for the organization; efficiently managing economic, social and environmental risks; reducing operating costs through better resource management throughout the supply chain; building customer loyalty and trust through dialogue and interaction; and ensuring business stability based on good relationships with key stakeholders [14].

Companies that follow the principles of sustainable development are more competitive, stable and successful in the market, because they are preferred by major customers, investors, public figures who understand the interdependence between the financial results of an organization and its non-financial programs. To evaluate and compare the performance of companies in sustainable development, indices of leading companies in this area were created, with the most famous and authoritative one being the Dow Jones Sustainability Index [15]. The sustainable development goals can be categorized into global, national, regional and individual enterprise goals. 
The sustainable development goals of industrial enterprises in the B2B market can be divided into: organizational and economic, marketing, technological, financial, environmental and social ones.

Setting the general (basic) goals of the enterprise is based on an assessment of the goals of all interested groups, their potential strength, aggressiveness, and mechanism of influence. Currently, there are two main approaches to setting the goals of strategic enterprise management [16]. The first one is the monistic approach, which is characterized by the desire to single out a common or main goal. This approach to strategic management has a number of advantages when solving short-term and uniquely purposefully oriented issues and can be applied to tackling individual strategic problems.

The second approach to setting the strategic management goals of an enterprise is a multipurpose one. It involves allocatiing a large number of goals that are equivalent in value in a hierarchical classification.

The second approach to setting strategic sustainable development goals is more efficient due to the complexity and necessity of integrated content, a medium-term planning horizon, the multidimensionality of socio-economic and production-economic problems, the dynamism of changes in the market situation in which enterprises operate.

However, it should be noted that the possibilities for sustainable development of an enterprise are influenced not only by relationships and processes that are implemented in the company's divisions. External factors that determine the possibilities of implementing the elements of enterprise sustainability are of great importance. These include economic factors, competition in product markets, technological innovation, legal factors, budgetary and financial national policy, availability of resources, and the state of the information environment [17].

When implementing sustainable marketing, industrial enterprises need to adapt and make the most of the opportunities that emerge in their environment. In this case, the goals of sustainable marketing for an enterprise are to monitor external factors, to identify opportunities and threats to development, and to make appropriate management decisions.

The main reason why a sustainable marketing strategy may be considered flawed is that an enterprise will not be able to fully convey the value of its strategy to recipients who have an impact on the company's activities. Thus, a long-term strategy solution requires new cyclical and regenerative marketing approaches that will create a sustainable enterprise for the synergistic effect of stakeholders.

Interested parties or persons in the context of the above statements can be called stakeholders (groups or individuals who can influence activities to achieve the goals of the enterprise or themselves may be influenced by it). In this regard, it is important to refer to works by E. Freeman, in which he studies the relationship between enterprises and stakeholders, and discusses the importance of taking into account the interests of all participants to create a long-term enterprise strategy [18].

In the theory of stakeholders, the contingent of stakeholders is defined as part of the environment and includes business owners, personnel or employees, business partners, investors, competitors, certain regulatory authorities, contact audiences, the media, and various public organizations [15]. This list is not limited only to these stakeholders, the composition and quantity may vary depending on the field of activity or the market in which the enterprise operates.

Stakeholder typology approaches have been constantly updated with new categories since the first studies of this phenomenon appeared. At the same time, since the theory of sustainable development based on the synergy of its participants is still very young, many definitions and classifications are superimposed and updated at the expense of each other. All stakeholders can be divided into two groups: internal and external ones. Internal stakeholders are important for the company as they directly influence the activities of the 
enterprise, the urgency and accuracy of product delivery or service provision. These include: cooperating stakeholders (founders); shareholders; top managers; different categories of staff; personnel who quit; owners (those who have a share of the business); supplier companies (external suppliers of goods and services and subcontractors); consulting and outsourcing organizations; contact organizations (strategic partners); educational community.

Interaction with external stakeholders is based on the indirect coverage of interests, but despite this, the group will become increasingly influential, taking an active approach to interaction with stakeholders. The current trend suggests that companies that are most successful in the field of external relations not only have better overall capabilities than their competitors, but also have special skills in organizing their external relations functions. This category should include:

- potential employees: a possible inflow of human capital;

- financiers: groups without interaction with which the enterprise could not exist (shareholders, investors, and banks);

- customers: they are not part of the organization and, as a rule, require the organization to meet their needs; they influence consumer choice;

- supporting suppliers: they are not part of the organization and, as a rule, require the organization to meet their requirements in relation to the company's products (raw materials, materials, consulting services, and infrastructure);

- rival company: enterprises competing in the same market or a similar niche;

- external controlling stakeholders: federal and municipal authorities and their departmental organizations;

- contact organizations: strategic partners;

- contact audiences: population, local authorities; charities and volunteer organizations;

- educational community: research centres; academic and pedagogical staff;

- information group: mass media, television and radio broadcasting; magazines, newspapers; the Internet;

- non-profit organizations: human rights enterprises; animal welfare enterprises; environmental protection enterprises, etc.

To develop a clear set of priorities, it is important to start with an analysis of what is most important to stakeholders throughout the value chain, with internal analysis and consultation with stakeholders, including clients, regulators and non-governmental organizations. This process should enable companies to identify the sustainability issues with the greatest long-term potential, and thus to create a system of strategic action, rather than a long list of vague desires.

\section{Discussion}

Since creating a sustainable enterprise involves transforming the entire value chain from supplying materials to product development, operations, sales and marketing, and end-life management, the stakeholder list can vary from enterprise to enterprise. The interests of stakeholders also differ depending on their goals and strategies. For some, it is a matter of meeting the needs of customers looking for the goods and services they need. For others, it is about overcoming pressure from stakeholders, such as investors, or their own corporate value system. For the third group, especially in the context of limited resources, this is a strategic imperative. Whatever the interest, sustainability has become a common prerogative, a requirement of the environment.

The determination of the most influential stakeholders is a key issue in the stakeholder approach to strategy creation. Managers expect that government agencies and their regulators, as well as customers, will have the greatest impact on the value of their 
companies [19]. The organization of external relations for industrial enterprises and their interaction with stakeholders are two basic factors to analyze the reactions of stakeholders to the business impact. Opportunities to improve and be more proactive in interactions provide a better understanding of stakeholder value. The stakeholder approach aims at aggregating the value required by stakeholders from an industrial enterprise. Stakeholder value refers to the value generated by business.

It can be noted that the creation of value for stakeholders has become a focus of attention. This value cannot be measured quantitatively, since it is formed as a result of aggregating changes in the subjective relationships (derived from the ranking of the attractiveness of various states of business) of the recipient to strategic business decisions $[20,21]$. Therefore, stakeholder value is a quality indicator.

According to the above, we consider it expedient to supplement the existing methods of developing a strategy for an industrial enterprise with a tool for assessing the stakeholder value based on planning sustainable development goals for each group.

In order to identify key stakeholders, it is worth applying the Salience Model proposed by Mitchell, Agle and Wood. The model is based on the construction of a matrix where the attributes of influence and significance intersect. The methodological toolkit of this model helps to formalize and implement the managerial impact on business development [22]. The Salience Model uses three parameters to classify stakeholders: power, legitimacy. and urgency. Mitchell, Agle and Wood associated each area in the Venn diagram with a specific type of stakeholder. In the continuous interconnection of parameters, seven subgroups are formed according to the importance of stakeholders. The latency attribute is typical for three of them, the expectation attribute is for two, and the categorical attribute is for one.

This creates major groups of enterprise stakeholders, each one with very different behaviours, resulting in different touchpoints that are beneficial to industrial enterprises. Latent groups are inactive and do not manifest themselves, but they have power; accordingly, the controlling group provides legitimacy, and the demanding group defines urgency. Since the capabilities of the enterprise are limited and the enterprise cannot direct its resources in all directions of interaction, one has to be content with a small amount of attributes. The full set of attributes also describes different ways of interaction that can be followed in their future strategies: waiting groups are divided into dominant (controlling power and legality), dependent (controlling legality and urgency) and dangerous ones (controlling power and urgency).

The call for more serious strategic decisions arises among company managers when there is a combination of two properties of stakeholders. But the most interesting and complex group are the stakeholders belonging to the categorical group as they have a threecategory focus. Due to this consolidation, the group is a key indicator of the company's strategic decisions.

Having identified the stakeholders, we monitor the current level of influence of stakeholders on the enterprise (Fig. 1). Expert and parametric methods can be efficient to determine the qualitative characteristics of this influence. The data obtained after evaluating the parameters is displayed on a radar diagram [23]. This stage can be graphically vizualized as the dependence of the above influence and the degree of dependence. It is an information and analytical tool to make management decisions related to the enterprise development strategy sustainability.

The next step is to identify the interests of each group in the field of sustainable development and to rank the stakeholders by priority of interests. 


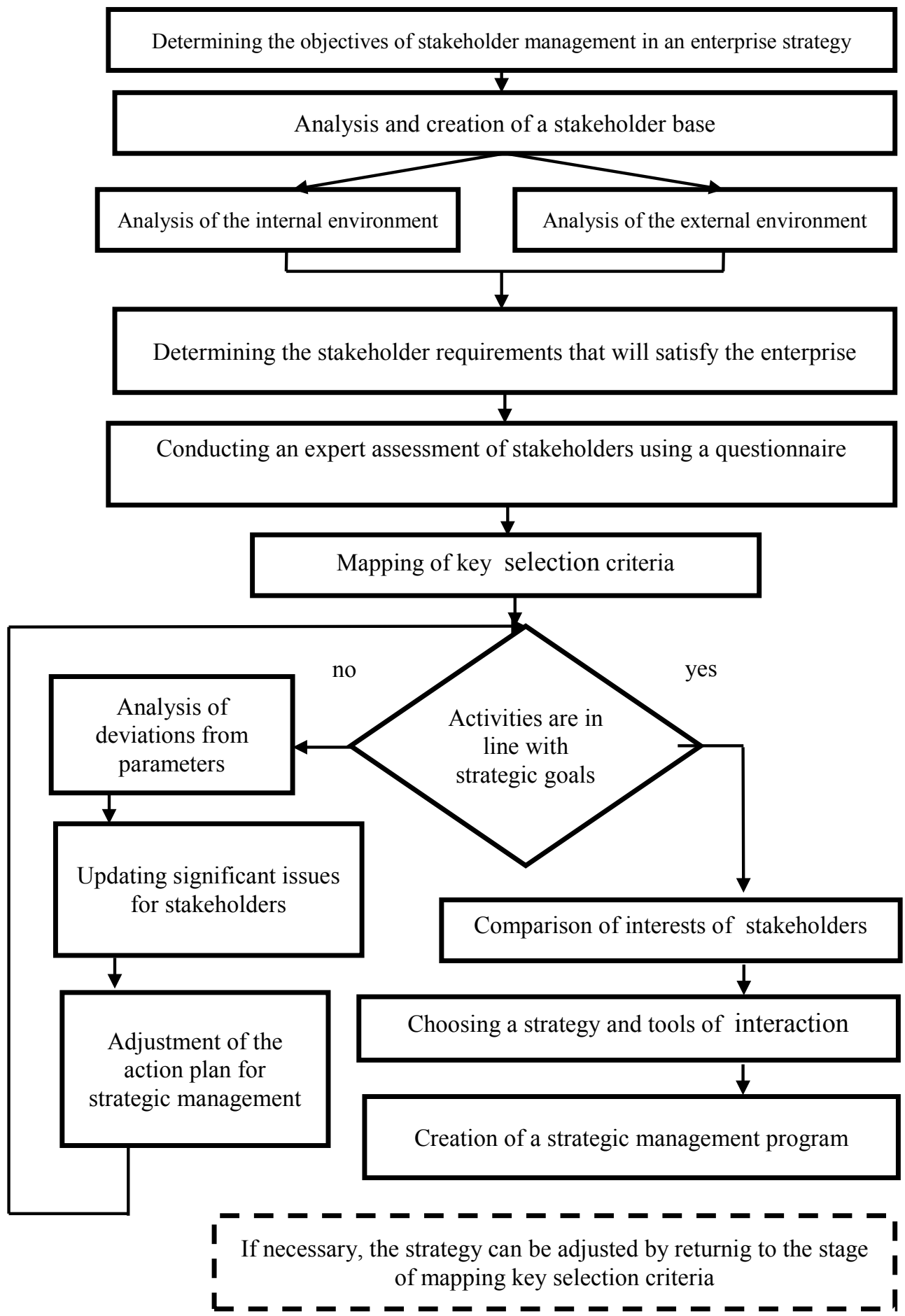

Fig. 1. Algorithm for the creation and selection of industrial enterprise strategies based on the concept of sustainable marketing. 
At this stage, it is worth considering that the influence of partners-suppliers and customers-enterprises is critical for the strategic and competitive development of industrial enterprises operating in the B2B market. However, determining the significance of sustainable development goals requires additional research of each group of stakeholders. The proposed stages make it possible to provide a better strategic approach to stakeholders interacting with the enterprise and allow it in the future to avoid the costs of manipulations, which are insignificant in the goal-setting of the stakeholders, while increasing the efficiency of activities due to the measures taken.

\section{Conclusion}

Thus, in our opinion, creating a strategy for an industrial enterprise in B2B markets based on sustainable marketing and the stakeholder approach is the most appropriate at the present time. Therefore, its principles formed the ground of the proposed algorithm to manage key stakeholders of the enterprise. Fig. 1 shows the algorithm providing a deeper insight into the stakeholders surrounding the enterprise, due to the fact that the interests of those participating in the business processes are taken into account, which subsequently will have a positive effect on meeting the strategic goal of the enterprise. This allows stakeholders and enterprises to avoid unnecessary expenses and to increase the efficiency of the developed programs.

The results that can be obtained when creating the strategy of an industrial enterprise based on the concept of sustainable marketing within the framework of the presented algorithm depend on the strategic goals of the enterprise. The proposed algorithm can help to obtain the following specific results from its implementation in practice: increasing sales growth; smoothing out risk situations; lower staff drain; growth of a positive image in the media; building a loyal audience with the potential for repeat purchases; increasing the technical and economic indicators of the enterprise. Understanding the expectations and requirements of stakeholders in the process of implementing the proposed algorithm to create and select strategies for an industrial enterprise facilitates satisfying the requests of stakeholders and contributes to the development of practical recommendations for the company to manage its stakeholders.

\section{References}

1. J.N. Sheth, A. Parvatiyar, Macromarketing (2020) DOI: 10.1177/0276146720961836

2. O.A. Pogrebova, E.A. Konnikov, O.U. Yuldasheva, Proceedings of SCM 2017 (2017) DOI: $10.1109 / \mathrm{SCM} .2017 .7970693$

3. K. Kashani, (Computer Press, Brno, 2007)

4. R.S. Tedlow, G.G. Jones, The Rise and Fall of Mass Marketing (Routledge, 2014)

5. Y. van Dam, P.J. Apeldoorn Macromarketing 16(2), $45-56$ (1996) DOI: $10.1177 / 027614679601600204$

6. M.J. Polonsky, “Green marketing," in Sustainable Solutions: Developing Products and Services for the Future (2017)

7. R.W. Mitchell, B. Wooliscroft, J.J. Higham, Macromarketing 30(2), 160-170 (2010) DOI: $10.1177 / 0276146710361928$

8. J.Z. Zhang, G.F. Watson, Industrial Marketing Management 88, 287-304 (2020) DOI: 10.1016/j.indmarman.2020.04.023

9. K. White, R. Habib, D.J. Hardisty, J. Mark (2019) DOI: 10.1177/0022242919825649 
10. Vinod Kumar, Zillur Rahman, A.A. Kazmi, Praveen Goyal, Procedia - Social and Behavioral Sciences 37, 482-489 (2012) DOI: 10.1016/j.sbspro.2012.03.313

11. R. Varadarajan, J. Acad. Mark. Sci. (2017) DOI: 10.1007/s11747-015-0461-6

12. O. Chkalova, M. Efremova, V. Lezhnin, A. Polukhina, M. Sheresheva, Entrep. Sustain. Issues (2019)

13. I. Krasyuk, T. Kirillova, S. Amakhina, ACM International Conference Proceeding Series (2019) DOI: 10.1145/3372177.3373304

14. A.G. Chofreh, F.A. Goni, J.J. Klemeš, M.N. Malik, H.H. Khan, J. Clean. Prod. (2020) DOI: $10.1016 /$ j.jclepro.2019.118655

15. Organisation for Economic Cooperation and Development, "Sustainable Manufacturing and Eco-Innovation: Framework, Practices and Measurement" (2009)

16. V. A. Bespalko, A. A. Voronov, and O. V. Martynenko, Int. J. Econ. Bus. Adm., (2019), DOI: 10.35808/ijeba/285.

17. R.K. Mitchell, G.R. Weaver, B.R. Agle, A.D. Bailey, J. Carlson, Acad. Manag. Rev. (2016) DOI: 10.5465/amr.2013.0486

18. Freeman R. E. Business Ethics Quarterly 18, 2 (2008)

19. B.M. Lyamin,I.A. Krasyuk, Smart Innovation, Systems and Technologies (2019) DOI: 10.1007/978-3-030-18553-4_49

20. Y. Klochkov, E. Klochkova, I. Krasyuk, S. Krymov, D. Gasyuk, N. Akobiya, ICRITO 2017 (2018) DOI: 10.1109/ICRITO.2017.8342414.

21. E. Nikolaeva, D. Pletnev, Journal of Advanced Research in Law and Economics 6(4), 768-774 (2015). doi:10.14505/jarle.v6.4(14).06

22. R.K. Mitchell, B.R. Agle, D.J. Wood, Acad. Manag. Rev. (1997) DOI: 10.5465/AMR.1997.9711022105

23. V.A. Bondarenko, A.A. Voronov, A.A. Zimina, A.V. Penyugalova, Eur. Res. Stud. J. (2018) 